\title{
Engineering As A Social Activity: Preparing Engineers To Thrive In The Changing World Of Work
}

Fredricka F. Joyner, Indiana University East, USA

Derek T.Y. Mann, Performance Psychology Group, LLC, USA

Todd Harris, PI Worldwide, USA

\begin{abstract}
Key macro-trends are combining to create a new work context for the practice of engineering. Telecommuting and virtual teams create myriad possibilities and challenges related to managing work and workers. Social network technology tools allow for unprecedented global, 24/7 collaboration. Globalization has created hyper-diverse organizations, magnifying the possibility for both generative creativity and destructive conflict. A growing body of research makes it clear that effectiveness in the changing world of work requires thinking differently and working differently. There is an emerging consensus that socio-cultural competence is an essential addition to the technical competence that has traditionally been identified as critical for engineers. Related to this, the value added to the work of engineering by the development of emotional intelligence (EI) competencies is gaining attention in the professional and the educational engineering literature. This paper describes a program for integrating emotional intelligence content into the curriculum in order to better prepare graduates to add value to their organizations and experience personal success working in the new normal. It also discusses the findings from a multi-year research study that measured the results of the program.
\end{abstract}

Keywords: Emotional Intelligence; EQ-i; Engineering Education; Engineering Curriculum Design; Predictive Index; Myers Briggs; Integrative Thinking; MBA

\section{INTRODUCTION}

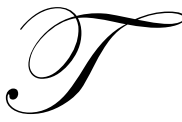

his paper contains three sections that, taken together, tell an important story. Part 1 introduces the concept of engineering as a social activity within the larger context of the changing world of work. This section goes on to explore some of the competencies that are being identified as critical for engineers to thrive within this context. Part 2 explores some research that highlights the challenges engineers face in the changing world of work based on the dominance of technical competencies among engineers. Part 3 presents a case study outlining an approach to the development of emotional intelligence competencies that has relevance for the education and on-going professional development of engineers.

\section{PART 1: THE CURRENT CONTEXT}

\section{Engineering As A Social Activity}

One recent morning I was talking with John Wall, Chief Technical Officer for Cummins, Inc. about how the work of engineering has evolved over the last decade. Cummins, Inc. describes itself as "a global power leader, a corporation of complementary business units that design, manufacture, distribute and service engines and related technologies, including fuel systems, controls, air handling, filtration, emission solutions and electrical power generation systems. Headquartered in Columbus, Indiana, (USA) Cummins serves customers in approximately 190 countries and territories through a network of more than 500 company-owned and independent distributor locations 
and approximately 5,200 dealer locations. Cummins reported a net income of $\$ 1.04$ billion in 2010" (Cummins, 2011). One factor that has contributed to Cummins' success is the company's commitment to developing and adopting cutting edge engineering approaches. Most notable among these is the development of global engineering teams that collaborate $24 / 7$ in virtual design and test labs.

As we discussed the ways in which Cummins is leveraging technology, Dr. Wall made an intriguing comment. He told me that as he visits Cummins' technical facilities around the globe, one of his key messages (or as he refers to it - his mantra) is "engineering is a social activity." To understand the changing work of engineering more deeply I turned to the literature, and found ample support for Wall's mantra.

\section{The Changing World Of Work}

Over the past several years, the world of work has undergone a fundamental transformation, resulting in what is being described by some as a "new normal." A recent study (Harris, 2011) identified a number of key macro-trends that are combining to create a new work context. At the top of the list are telecommuting and virtual teams; increased collaboration; and, globalization and diversity. Of course, these trends do not stand alone, but inter-relate and amplify each other. And, these trends have a profound impact on the practice of engineering. Telecommuting and virtual teams create myriad possibilities and challenges related to managing work and workers. Social network technology tools allow for unprecedented global, 24/7 collaboration. Globalization has created hyper-diverse organizations, magnifying the possibility for both generative creativity and destructive conflict.

Lappalainen (2009) describes the confluence of these trends in the following way: “ . interdisciplinarity and globalization have transformed engineering communities into collaboration arenas extending beyond uniform national, cultural, contextual and disciplinary settings and structures" (p. 123). Beder (1998) states that "The image of the engineer as technically-inclined and socially introverted is increasingly outdated. Engineers manage sociotechnological systems; they bring together, work with, coordinate, manipulate, and build upon various elements of a system which include not only things, but also social organizations, laws, financial and cost considerations, scientific theories, natural resources, and public perception" (p. 57). These descriptions make it clear that effectiveness in the new world of work requires thinking differently and working differently and is supported by both technical and social competence.

An awareness of the need for thinking and working differently is growing out of the collective appreciation of the implications of the new work context. Martin (2010) describes this as "integrative thinking" - a holistic perspective that moves away from 'either/or' decision making toward considering options, welcoming complexity, and relying less on narrowly defined disciplinary constructs. This awareness is creating a fundamental shift away from the application of formulaic tools and models that are prescriptive in nature and do not adequately recognize the importance of contextual variables. Emerging integrative work approaches are based on an appreciation of complex system connections, generative critical thinking and problem solving, unprecedented levels of collaboration across traditional boundaries, and, effective engagement of an increasingly diverse set of stakeholders. Furthermore, there is an emotional component at the core of this shift because integrative thinking engages ideas both intellectually and emotionally (Martin, 2007).

\section{Emerging Competency Frameworks}

Recognition of the fundamental changes in the work of engineering has, over the past several years, produced an active conversation regarding the competencies related to effective engineering practice (Lappalainen, 2009; El-Baz \& El-Sayegh, 2010; Crumpton-Young et al., 2010; National Academy of Engineering, 2004; Naguib, 2007; Trevelyan \& Tilli, 2007; Beder, 1999; King \& Skakoon, 2010; De Graaff \& Ravesteijn, 2001). There is an emerging consensus that socio-cultural competence is an essential addition to the technical competence that has traditionally been identified as critical. For example:

- In making a case for the importance of communication as a part of the engineering skill set, Lappalainen (2009) points out that "Engineers no longer manage their daily task with plain substance expertise; instead they must be adept at communication, collaboration, networking, feedback provision and reception, teamwork, lifelong learning, and cultural understanding" (p. 123). 
- $\quad$ After conducting a broad-based survey that included both practicing and student engineers and focused on engineers in leadership roles, Crumpton-Young et al. (2010) concluded that competencies related to "people skills" - such as dealing with differences, working cross-functionally, facilitation, and conflict resolution - were the most important areas of preparation.

- In their study of personality characteristics of engineers, Van Der Molen et al. (2007) concluded that "more attention should be paid to the development of interpersonal skills" (p. 495).

- $\quad$ El-Baz \& El-Sayegh (2010) built and tested a comprehensive competency model that integrated past research and field experience. They found that interpersonal competencies were of critical importance.

These examples all support the notion that engineering does indeed have an important component of social activity. The competencies described in these studies, and others like them, "represent the socio-cultural dimensions that are becoming increasingly important as globalization intensifies the demands for flexible, socially adept and communicative engineering communities" (Lappalainen, 2009).

\section{PART 2: THE DOMINANCE OF TECHNICAL COMPETENCE AMONG ENGINEERS}

\section{Most Engineers Have A Strong Technical Orientation}

Over the next few weeks, I pondered Dr. Wall's comment as I reflected on my experience providing leadership development training to engineering and technical managers. The four-day, participative training session is delivered over two months and explores content related to key leadership topics such as change, setting expectations, conflict, and coaching. Over the last four years, over 1,000 managers from one large Fortune 500 company have participated in the training, which has been delivered at several sites in the US and in Europe. As a key component of the training experience, participants complete the Predictive Index ${ }^{\circledR}$ assessment instrument and explore their results in the context of increasing their managerial effectiveness.

\section{Overview of the Predictive Index Instrument}

The Predictive Index, or PI®, measures a set of fundamental motivational needs related to personality. It is a theory-based, self-report measurement of normal, adult, work-related personality, and has been developed and validated exclusively for use within occupational and organizational populations. The PI employs a free-choice (as opposed to forced-choice) response format, in which individuals are presented with two lists of descriptive adjectives, both containing the same 86 items, and are asked to endorse those which they feel describe them (the "SELF" domain), and then those which they feel coincide with how they feel others expect them to behave (the "SELF-CONCEPT" domain). Summing across these two domains yields a third implied domain (the "SYNTHESIS"), which can be interpreted as reflecting an employee's observable behavior in the workplace. The assessment is un-timed, generally takes approximately five to ten minutes to complete, and is available in paper-andpencil, desktop and Internet formats. The PI has been in wide-spread commercial use since 1955, is currently available in over 60 different languages, and is used by clients in over 120 different countries. The PI has a long and extensive history of being used in engineering and manufacturing settings, and is often integrated with quality initiatives such as Six Sigma, TQM, Lean Manufacturing, and others.

Of the many common personality traits measured by the PI, five may be particularly useful in helping to understand the challenges facing engineers within the context of changes taking place in the engineering environment:

1. Factor A: DOMINANCE: The degree to which an individual seeks to control his or her environment. Individuals who score high on this dimension are independent, assertive and self-confident. Individuals who score low on this dimension are agreeable, cooperative, accommodating, and are often seen as consummate team players.

2. Factor B: EXTROVERSION: The degree to which an individual seeks social interaction with other people. Individuals who score high on this dimension are outgoing, persuasive and socially-poised. Individuals who score low on this dimension are serious, introspective, analytical and task-oriented. 
3. Factor C: PATIENCE: The degree to which an individual seeks consistency and stability in his or her environment. Individuals who score high on this dimension are patient, consistent and deliberate. Individuals who score high also tend to value the social connections that come with being part of a team effort. Individuals who score low on this dimension are fast-paced, urgent and intense.

4. Factor D: FORMALITY: The degree to which an individual seeks to conform to formal rules and structure. Individuals who score high on this dimension are organized, precise and self-disciplined. Individuals who score low on this dimension are informal, casual and uninhibited.

5. Factor E: DECISION-MAKING: Measures how an individual processes information and makes decisions. Individuals who score high on this dimension are objective, logical and are primarily influenced by facts and data. Individuals who score low on this dimension are subjective, intuitive and are primarily influenced by feelings and emotions.

\section{Predictive Index Aggregate Data}

The following data table summarizes the PI scores of the participants in the training sessions described above.

Table 1: Predictive Index Aggregate Data $(\mathrm{N}=1,114)$

\begin{tabular}{|l|c|c|}
\hline \multicolumn{1}{|c|}{ PI Factor } & Percent Low & Percent High \\
\hline A: Dominance & $38 \%$ & $62 \%$ \\
\hline B: Extroversion & $72 \%$ & $28 \%$ \\
\hline C: Patience & $68 \%$ & $32 \%$ \\
\hline D: Formality & $17 \%$ & $83 \%$ \\
\hline E: Decision-Making & $36 \%$ & $64 \%$ \\
\hline
\end{tabular}

In examining the PI's of this population in the aggregate, a number of clear trends are observed:

- $\quad$ There is a strong analytical and technical focus to the group. Many of these individuals will be actionoriented, will enjoy diagnosis and problem-solving, and will have a creative and inquiring approach to their work and to the world around them. They will often be assertive, independent, self-confident and competitive. They will want to control their own activities, and will be reluctant to delegate any meaningful authority. Additionally, because of their focus on tasks and things, they will not have as strong a need to engage in the social and interpersonal elements of work, and social recognition and status will not have a particularly strong impact on their behavior.

- The majority of these individuals will work at a faster-than-average pace, will be impatient with routines, will embrace variety and change as opposed to consistency, and will work with a sense of urgency. They appreciate freedom - freedom from repetition, freedom of movement and mobility, and freedom to change priorities as the situation dictates. They are often impatient for results, and are intolerant of delays - they are driven to "cut through the red tape" and get on with things. They may not naturally value being part of a team or a group.

- $\quad$ A large number of these individuals (> 80\%) score higher than average working population norms on the Predictive Index Factor D (FORMALITY) measure. This suggests that when communicating and working with others, they will tend to be reserved, formal and quiet, with a serious and disciplined approach. They will prefer to stick with the facts, will be sincere, and will say exactly what they mean. Because they want to do the right thing, and are very concerned with the accuracy and overall quality of their work, they will be sensitive to any criticism.

- When making decisions, the majority of these employees will strongly emphasize objective thinking, and will tend to be logical, practical and realistic when deciding upon a course of action. There can be a tendency to overlook or discount the "emotional" or "human" components of decisions, and the consequences of those decisions on others, including co-workers.

While these results are based on a study of approximately 1100 engineering and technical managers in one company, other studies have identified similar patterns. A Dutch study (Van Der Molen et al., 2007) employed a 
five-factor personality inventory of Dutch origin and concluded that "it [the study] demonstrated that engineers are more autonomous and less friendly than ordinary people are. The latter characteristic may be somewhat problematic in interpersonal relations, because these relations, if effective, often imply a level of agreeableness of the partners involved that engineers not always are able to provide. Here a practical implication of the findings might be that in the education of engineering students and in postgraduate training more attention should be paid to the development of interpersonal skills" (p. 499). Another study (Culp \& Smith, 2009) employed the Myers-Briggs Type Indicator with a group of consulting engineers. The study found that almost $74 \%$ of the sample had a Thinking Preference, compared to about $40 \%$ in the general U.S. population (p. 67). Individuals with a Thinking Preference look at the logical consequences of a decision. They like to find a standard or a principle that applies to all similar situations. They are impressed with logical and scientific arguments and feel that it is more important to be right than liked. The authors concluded that the patterns identified by the study "can create communication challenges" (65).

Taken together, these studies suggest that, while the work of engineering includes an increasingly critical social component, many engineers have a strong technical focus. The following case study describes an approach that was successfully used to develop emotional intelligence competencies in MBA students. The methodology described would easily transfer to the development of engineers.

\section{PART 3: DEVELOPING EMOTIONAL INTELLIGENCE: A CASE STUDY}

\section{A Transferable Model For Competency Development}

Over the past two decades an escalating interest in the construct of emotional intelligence (EI) has made its way into the popular press, professional press, and peer reviewed journals. Not surprisingly, an interest in EI is also gaining ground in academic settings (Parker, Duffy, Wood, Bond \& Hogan, 2002; Parker, Hogan, Eastabrook, Oke $\&$ Wood, 2006; Parker, Saklofske, Wood \& Eastabrook, 2005). Specific to engineering, the value added to the work of engineering by the development of emotional intelligence (EI) competencies is gaining attention in the professional and the educational engineering literature. On the professional side, in addition to awareness-building articles (King \& Skakoon, 2010; Palethorpe, 2006; Naguib, 2007), studies are beginning to appear in the literature. For example, Sunindijo et al. (2007) published a study of EI competencies in project managers and project engineers in Thailand. They found that individuals with higher EI scores used more communication strategies that "opened the possibility of getting the best from people." Their study also linked higher EI to the ability to stimulate team performance and innovation (p. 170).

On the engineering education side, there is a call for the development of more "soft" skills as well as the need for new pedagogical approaches to accomplish this development (Butun et al., 2009; Verzat et al., 2009; Crumpton-Young et al., 2010). Verzat et al. (2009) argue that "the creation of 'bilingual' graduates who have dual technical and managerial competencies is thwarted by students' inferior teamwork and interpersonal skills. Their study revealed that French engineering students struggle with team-based, innovation projects and they urge the development of new pedagogical approaches.

The emerging interest in the development of EI competencies within the field of engineering makes the following case study particularly relevant. This case study documents how one MBA program piloted the integration of emotional intelligence (EI) content into its curriculum in order to better prepare its graduates to add value to their organizations and experience personal success working in the new work context. The case study also discusses the findings from a multi-year research study that measured the results of the pilot program. The research was conducted using one of the most widely used instruments for measuring emotional intelligence, the Bar-On Emotional Quotient Inventory (EQ-i) (Bar-On, 1997), to identify significant changes between the beginning and the end of the program in the aggregate measures of emotional intelligence competencies.

\section{Program Background}

Several major longitudinal studies have laid a sound theoretical foundation supporting the development of EI competencies as a component of the MBA curriculum (Boyatzis, Stubbs \& Taylor, 2002; Boyatzis \& Saatcioglu, 2008). This case study will describe why and how one MBA program took theory to practice and piloted the integration of content designed to develop competencies related to emotional intelligence into its curriculum. 
This MBA has been offered by the regional campus of a major university in the Midwest since 2001. It is a 45 credit, general management program typically completed in 33 months. It is cohort-driven with approximately 25 students in each cohort. While delivered on-site, the program is technology-enhanced. The program is career integrated, and, while most students are at their first or second career milestone, work experience varies from $1-33$ years at the point of admission. Students in the program are diverse representing 15 communities of residence, 45 employers, and 65 undergraduate institutions. Due to the mix of regional employers, a significant percentage of students work in technology or engineering environments. Approximately ten percent of the students hold a previous Master's degree.

\section{Theoretical Foundation And Context - Overview Of Emotional Intelligence}

In order to understand the context of this case study, let's begin with a whistle-stop discussion of the theoretical underpinnings of EI.

The construct of emotional intelligence was first defined by Salovey and Mayer (1990) as "the ability to monitor one's own and others' feelings and emotions, to discriminate among them and to use this information to guide one's thinking and action" (p. 189). Salovey and Mayer's original definition brought together the constructs of emotions and intelligence by viewing emotions as useful sources of information that help individuals make sense of their social environment. Mayer and Salovey originally conceptualized emotional intelligence as a group of related mental abilities that includes social, personal, and practical intelligences. They labeled these intellectual capacities as "hot cognitions" because they operate and deal with matters of personal, emotional importance to the individual (Mayer, Salovey, \& Caruso, 2004).

Goleman (1995) and Bar-On (1997) later broadened the notion of emotional intelligence to include an array of skills and traits that help people adapt to all aspects of life. Goleman defines emotional intelligence as the capacity to recognize our own feelings and those of others, to motivate ourselves, and to skillfully manage emotions in ourselves and in our relationships. Whereas, Bar-On (1997) defined emotional intelligence as an array of noncognitive skills and abilities that determines how effectively we understand and express ourselves, understand others and relate to them, and cope with daily demands. Although both of these definitions included emotion-related qualities such as emotional self-awareness, social awareness, and emotional understanding, many additional qualities such as reality testing, assertiveness, social responsibility, motivation, and independence are added within the Bar-on (EQ-i) framework.

\section{Development Protocol}

During the multi-year pilot (spanning 2007 - 2010), content related to the development of EI competencies was integrated into all three years of the MBA curriculum. The content was linked, with each new content input building on and extending the content previously introduced, thus creating a "content thread." The decision to take such a comprehensive approach - not restricting the content to one course but integrating it into all three years of the program - was based on a belief in the fundamental connection between these competencies and personal, career, and ultimately business success discussed in the previous section.

The EI development protocol that comprised this content thread included the following steps:

- $\quad$ Develop deeper self-awareness in order to more fully answer the question: Who am I?

- Take time to identify the challenges, opportunities, expectations, and demands of the current context in order to more fully answer the question: What are the most important components of my context?

- Identify development opportunities and leverage points based on the combination of self-knowledge and the demands of the current context in response to the question: How can I increase my effectiveness?

- $\quad$ Establish and implement a development plan. 


\section{Instruments Used}

Information from three instruments provided foundational information for this content thread. These instruments were the Myers-Briggs Type Indicator ${ }^{\circledR}$ (MBTI), the Predictive Index ${ }^{\circledR}(\mathrm{PI})$, and the EQ-i. The MBTI and the PI provide an understanding of fundamental aspects of an individual's personality, helping answer the question Who am I? The EQ-i identifies opportunities for competency development and helps answer the question How can I increase my effectiveness?

First published in the early 1960s, the MBTI is generally recognized as the most widely used personality assessment (Myers, McCaulley \& Quenk, 1998). It is a personality inventory that measures individual psychological preferences on four key scales or dichotomies. These scales provide information on how an individual perceives the world and makes decisions. The PI, in wide-spread use since 1955, measures a set of fundamental motivational needs related to control, social interaction, pace, and risk (Harris, Tracy \& Fisher, 2010). Taken together, these two instruments provide an individual with insight into fundamental aspects of his/her personality that are believed to be relatively stable over time. They help to develop an understanding of self in relation to fundamental questions such as:

- Where do I get my energy?

- What information to I draw upon when making decisions?

- What is my preferred work pace?

- What is my comfort level with ambiguity and decision-making risk?

- What is my level of interest in making social connections with others?

- $\quad$ Am I more interested in keeping options open or gaining closure?

- How important is it for me to exert influence over people and events?

- Am I more comfortable as an individual operator or as a member of a team?

These questions address preferences and motivational drives that provide a starting point for developing deeper self-awareness and a fuller response to the question Who am I?

The EQ-i will be discussed in more detail in a subsequent section.

\section{Program Design}

In order to work through the three questions - Who am I? What are the important components of my context? and How can I increase my effectiveness? - key content milestones were designed as follows:

Milestone 1 - Orientation. During the orientation to the MBA program, the focus on the development of EI competencies, and the supporting business case, was introduced and discussed. For many of the students, this was their first exposure to the concept of a link between the explicit focus on the development of EI competencies and career and business success. The students then completed the three key instruments included in the content thread: the MBTI, the PI, and the EQ-i.

Milestone 2 - Who Am I? and What are the important components of my context? Early in the first semester, students attended a weekend intensive seminar entitled HR Tools for Personal Development that incorporated the MBTI and the PI. The focus of the intensive seminar was on developing a deeper understanding of fundamental personality traits and preferences. It also afforded participants an opportunity to explore and identify challenges, opportunities, and priorities in both a personal and professional context.

Completion of a final deliverable provided students with an opportunity to begin synthesizing their learning as it relates to the connections between self-awareness and career success. The instructions for that deliverable were as follows: 
After reviewing the PI and the MBTI information, please discuss the following:

- Generally speaking, one to three ways in which the PI® and/or the MBTI® might be useful in a business setting.

- One thing about your "profile" or "type" that could possibly serve you well in being successful in school and/or in a business setting.

- Ideas you have about how you can use this possible "strength" to your advantage.

- One thing about your "profile" or "type" that could possibly be a challenge for you in being successful in school and/or in a business setting.

- Ideas you have about strategies you could use so that the "challenge" doesn't get in the way of your success.

Milestone 3 - How can I increase my effectiveness? At approximately the halfway point in the program, the students participated in a second weekend intensive seminar specifically on the competencies that comprise the EQi. While it built on the first weekend intensive seminar's focus on self-awareness and personal development, the second intensive seminar was designed to focus more fully on career and professional development priorities. A training manual entitled $E Q \& Y o u$ (Cannon, 1999) provided the format for the intensive seminar. Based on the results of their EQ-i assessment, students created a professional development plan and participated in a one-on-one coaching session with the course instructor. The assignment was as follows:

- $\quad$ Understand Context

- Reflect on the key work/life challenges that you will be facing over the next $12-18$ months.

- Review and revise (if needed) your personal Leadership Philosophy.

- $\quad$ Assess

○ Review EQ-i results.

- Review your MBTI, PI, and any relevant performance feedback that you have received as a part of your job.

- $\quad$ Analyze and Prioritize

○ Identify $1-3$ target competencies.

- Plan

- Complete a Competency Development Plan for each of the priority competencies.

- Implement

○ Implement and reflect upon at least one of the developmental activities.

- $\quad$ Evaluate

- Schedule a one-on-one coaching session with course instructor to review the plan and developmental activities in the context of educational and career goals.

Milestone 4 - Self analysis of pre-and post-EQ-i scores. In the final semester of the program, as a part of a Leadership and Ethics course, students again took the EQ-i and completed an in-depth written analysis of their preand post-program scores. They were asked to comment on/address the following:

- $\quad$ Discuss the context of the last 2 - 3 years - major changes, experiences, areas of focus, and any other relevant information.

- Compare the results of the two assessments. Graphs and statistical analysis can be used here. Identify changes at the overall, composite scale, and sub-scale levels.

- $\quad$ Provide a detailed discussion of any changes identified. What meaning do you make of the changes? Make connections to the development plan you created based on the first assessment, any work-related development activities, developmental work assignments, or other activities. I am looking for an in-depth discussion here.

- Discuss any meaningful connections to the key models and conceptual frameworks you have worked with during the program.

- Discuss implications of this assessment based on what is on your $1-3$ year horizon.

- Discuss anything else that you feel is relevant. 
- $\quad$ Make the most of this developmental opportunity.

\section{Measurement Strategy}

A research study (ultimately including 55 students) was designed to measure the efficacy of integrating emotional intelligence training into the program. The study focused on the research question, can significant changes be seen between the beginning and the end of the program in the aggregate measures of emotional intelligence competencies?

\section{Research Methods} as follows:

Changes were measured by administering the EQ-i pre- and post-program. The data collection method was

- During orientation, prior to any content delivery, the purpose of the study was generally explained. Students were encouraged to be candid as they completed the instrumentation and were ensured of the confidentiality of their responses.

- $\quad$ Students completed the informed consent document and a demographic information sheet.

- $\quad$ Students completed the EQ-i online.

- The individual reports were scored online and the results downloaded.

- $\quad$ In the final semester of the program, students once again completed the EQ-i online.

- $\quad$ The individual reports were scored online and the results downloaded.

- $\quad$ Both pre- and post-program results were loaded into a spreadsheet and merged with the demographic data and pre- and post-program GPAs.

- $\quad$ After the information was merged, participant names were replaced with a numbering system so specific results could not be linked back to a specific individual.

\section{Measurement Instrument - The EQ-i}

The EQ-i is a self-report measure and is generally described as a skills-based model of EI. The Bar-On model (1997) involves an array of personal, emotional, and social abilities and skills. The EQ-i is comprised of 125 relatively short statements, in which responses are provided on a 5-point Likert scale ranging from "Very Often True of Me or True of Me" to "Very Seldom True of Me or Not True of Me." The EQ-i raw scores are converted into standard scores based on a mean of 100 and a standard deviation of 15 (Bar-On, 1997). The total EQ score breaks down into 15 content scale scores, which are clustered into five composite scores. The composite scores are Intrapersonal, Interpersonal, Stress Management, Adaptability, and General Mood. The subscales are Emotional Self-Awareness, Assertiveness, Self-Regard, Self-Actualization, Independence, Empathy, Interpersonal Relationship, Social Responsibility, Stress Tolerance, Impulse Control, Problem Solving, Flexibility, Reality Testing, Optimism, and Happiness (see Table 1). A higher score on any individual composite or subscale (or the total EQ-i score) implies stronger EI skills and a more positive prediction for effective functioning in meeting demands and challenges. Conversely, a lower EQ-i score suggests poorer EI skills and a reduced ability to be effective in meeting demands and challenges (Bar-On, 1997).

The reliability of the EQ-i has been examined by a number of researchers (Matthews, Zeidner, \& Roberts, 2002; Newsome, Day, \& Cantano, 2000; Petrides \& Furnham, 2000), with a consensus that the instrument is reliable, consistent, and stable. Bar-On (1997) reported that the internal consistency reliability of the overall EQ-i was 0.76 and the test-retest reliability was 0.85 after one month and 0.75 after four months. Additionally, several research studies have been conducted using the EQ-i to determine its construct validity and have shown a meaningful pattern of convergent validity with measures of psychological well-being and alexithymia (Dawda \& Hart, 2000), as well as with other measures of emotional and social intelligence (Bar-On, 2004). The EQ-i has also shown adequate discriminant validity with measures of cognitive ability (Bar-On, 2004; Van Rooy, Viswesvaran, \& Pluta, 2005) and personality (Van Rooy \& Viswesvaran, 2004). 
In regards to criterion validity, Slaski and Cartwright (2002) found that the EQ-i was significantly correlated with morale $(0.55)$, stress $(0.41)$, general health $(0.50)$, and supervisor ratings of performance $(0.22)$ in their study of retail managers. In another study of UK managers, Slaski and Cartwright (2003) found that training in emotional intelligence resulted in increased EQ-i scores and improved health and well-being.

Table 2: Emotional Quotient Inventory (EQ-i) Scales And Measurement Characteristics

\begin{tabular}{|c|c|}
\hline \multicolumn{1}{|c|}{ EQ-i Scales } & \multicolumn{1}{c|}{ EI Skills Assessed by Each EQ-i Scale } \\
\hline Intrapersonal & Self-awareness and self expression: \\
\hline Self-Regard & To accurately perceive, understand, and accept oneself \\
\hline Emotional Self-Awareness & To be aware of and understand one's emotions \\
\hline Assertiveness & To effectively and constructively express one's emotions and oneself \\
\hline Independence & To be self-reliant and free of emotional dependency on others \\
\hline Self-Actualization & To strive to achieve personal goals and actualize one's potential \\
\hline Interpersonal & Social awareness and Interpersonal relationship: \\
\hline Empathy & To be aware of and understand how others feel \\
\hline Social Responsibility & To identify with one's social group and cooperate with others \\
\hline Interpersonal Relationship & To establish mutually satisfying relationships and relate well with others \\
\hline Stress Management & Emotional management and regulation: \\
\hline Stress Tolerance & To effectively and constructively manage emotions \\
\hline Impulse Control & To effectively and constructively control emotions \\
\hline Adaptability & Change management: \\
\hline Reality-Testing & To objectively validate one's feelings and thinking with external reality \\
\hline Flexibility & To adapt and adjust one's feelings and thinking to new situations \\
\hline Problem-Solving & To effectively solve problems of a personal and interpersonal nature \\
\hline General Mood & Self-motivation: \\
\hline Optimism & To be positive and look at the brighter side of life \\
\hline Happiness & To feel content with oneself and life in general \\
\hline & \\
\hline
\end{tabular}

\section{Results}

While the pilot program did not include a discreet control group, the EQ-i normative data base provided a valid and appropriate comparison group for the purposes of analyzing results. The EQ-i has been stratified and normed on a population consisting of nearly 4,000 participants from across North America, providing the normative sample that was used as a comparison group to identify meaningful change over time. In a comparison of preprogram EQ-i scores from the MBA students to that of the EQ-i normative sample (Table 3), the males in the sample scored significantly $(p<.05)$ lower than the norm on self-actualization and interpersonal relationships, with no notable differences evident between females and the EQ-i normative sample. However, when comparing the postprogram results of both males and females to the normative population, males scored significantly $(p<.05)$ higher than the normative population on assertiveness, adaptability, flexibility, and problem solving. Moreover, females 
scored significantly $(p<.05)$ higher than the normative population on assertiveness, stress tolerance, and flexibility. (Note: While gender differences are noted as a part of the analysis methodology, the drivers for these differences were not a part of the scope of this study.)

To assess the efficacy of the training and awareness protocol outlined in the previous section, a repeatedmeasures ANOVA was conducted. The results indicate a significant improvement in emotional and social functioning as measured by improvement of all EQ-i competencies, except for the dimensions of independence, selfregard, and self-actualization (Table 4).

Lastly, to determine the impact that the EI training may have on academic performance, pre- and posttraining GPA was analyzed across gender using a 2 x 2 repeated-measures ANOVA with axes of gender (male, female) and time (pre, post). Results indicate a significant improvement in GPA across time $(F(1,52)=76.54, p=$ $.001)$. However, the gender-x-time interaction was not significant $(F(1,52)=.164, p=.688)$, suggesting that both males and females were equally impacted by the effects of the training protocol over time.

The comparison of the pre- and post-training program results of the MBA students to the EQ-i normative data base suggest that, while there were some gender-related differences, participation in the EI awareness and training protocol had a positive influence on the development of key EI competencies. The results of the repeatedmeasure ANOVA suggest improvement in emotional and social functioning as measured by a significant increase in most of the competencies measured by the EQ-i. Finally, the analysis of pre- and post-program GPA suggests that the development of EI competencies has a positive impact on academic success.

Table 3: Differences in EI Development

\begin{tabular}{|c|c|c|c|c|c|c|c|c|}
\hline \multirow{3}{*}{$\begin{array}{l}\mathrm{N}=55 \\
\\
\quad \text { EQ-i Scales }\end{array}$} & \multicolumn{4}{|c|}{ Pre-Test } & \multicolumn{4}{|c|}{ Post-Test } \\
\hline & \multicolumn{2}{|c|}{ Males } & \multicolumn{2}{|c|}{ Females } & \multicolumn{2}{|c|}{ Males } & \multicolumn{2}{|c|}{ Females } \\
\hline & Mean & SD & Mean & $\mathrm{SD}$ & Mean & $\mathrm{SD}$ & Mean & $\mathrm{SD}$ \\
\hline TOTAL EQ-i & 97.3 & 13.6 & 100.1 & 10.8 & 102.5 & 10.7 & 104.7 & 11.7 \\
\hline INTRApersonal & 97.4 & 13.3 & 102.7 & 11.9 & 102.6 & 11.3 & 105.3 & 12.9 \\
\hline Emotional Self Awareness & 97.9 & 14.7 & 98.8 & 13.5 & 102.7 & 12.7 & 105.9 & 13.4 \\
\hline Assertiveness & 98.5 & 14 & 103.7 & 12.3 & $104.7 *$ & 11.6 & $108.6^{*}$ & 11.4 \\
\hline Independence & 100.1 & 12.5 & 103.6 & 7.4 & 102.9 & 14.3 & 103.6 & 11.2 \\
\hline Self-Regard & 97.7 & 12.4 & 105.4 & 14.6 & 101.1 & 11.2 & 103.5 & 14.7 \\
\hline Self-Actualization & $96.3 *$ & 12.7 & 99.6 & 12.3 & 100 & 11.6 & 100.5 & 12.7 \\
\hline INTERpersonal & $97.4 *$ & 13 & 96.6 & 11.7 & 100.6 & 12.1 & 103.6 & 11.8 \\
\hline Empathy & 98.5 & 16.6 & 94.8 & 10.7 & 101.2 & 14.7 & 102.3 & 13.4 \\
\hline Social Responisbility & 100.2 & 13.6 & 99.4 & 7.2 & 102.7 & 12.4 & 103.2 & 10.1 \\
\hline Interpersonal Relationships & 96 & 12.7 & 96.9 & 16.1 & 99.2 & 13.1 & 103.4 & 13 \\
\hline ADAPTABILITY & 98.8 & 14.3 & 99.7 & 11.8 & $104.5^{*}$ & 11.2 & 104.8 & 10.8 \\
\hline Problem Solving & 99.3 & 11.5 & 96.7 & 6.4 & $104.3^{*}$ & 12.2 & 101.1 & 8 \\
\hline Reality Testing & 98.2 & 14.4 & 99.8 & 14.3 & 103.3 & 12.4 & 102.9 & 13.7 \\
\hline Flexibility & 99.8 & 16 & 102.8 & 14.1 & $103.5^{*}$ & 11.2 & $107.6^{*}$ & 11.3 \\
\hline STRESS MANAGEMENT & 98.4 & 14.4 & 99.8 & 10.1 & 102 & 12.1 & 104.6 & 11.4 \\
\hline Stress Tolerance & 97.9 & 15.6 & 101.7 & 7.2 & 100.9 & 13.4 & $105.4^{*}$ & 10 \\
\hline Impulse Control & 99.3 & 14.1 & 97.9 & 13.5 & 102.5 & 13.4 & 101.8 & 14.4 \\
\hline GENERAL MOOD & 97.6 & 14.4 & 99.6 & 13.6 & 101.2 & 11.2 & 101.9 & 14.9 \\
\hline Happiness & 98.7 & 15.6 & 99 & 15 & 101.2 & 12 & 102.4 & 16.2 \\
\hline Optimism & 97.5 & 12.9 & 101.5 & 12 & 101.8 & 11.9 & 102.1 & 12.7 \\
\hline
\end{tabular}

* Denotes significant difference from the population norm. 
Table 4: EI Subscale Development Over Time

\begin{tabular}{l|cc|cc|c|c}
\hline \multirow{2}{*}{ EQ-i Scales } & \multicolumn{2}{c|}{ Pre-Test } & \multicolumn{2}{c|}{ Post-Test } & \multicolumn{2}{c}{ Sig } \\
\cline { 2 - 7 } & Mean & SD & Mean & SD & F & 0.001 \\
TOTAL EQ-i & 97.9 & 13 & 103 & 10.9 & 15.3 & 0.001 \\
INTRApersonal & 98.6 & 13.1 & 103.3 & 11.7 & 15.9 & 0.001 \\
Emotional Self Awareness & 98.1 & 14.4 & 103.5 & 12.8 & 15.8 & 0.001 \\
Assertiveness & 99.8 & 13.7 & 105.7 & 11.6 & 21.6 & 0.129 \\
Independence & 101 & 11.5 & 103.1 & 13.5 & 2.4 & 0.091 \\
Self-Regard & 99.5 & 13.2 & 101.7 & 12.1 & 2.9 & 0.038 \\
Self-Actualization & 97.1 & 12.6 & 100 & 11.8 & 4.5 & 0.001 \\
INTERpersonal & 97.2 & 12.6 & 101.4 & 12 & 12.5 & 0.021 \\
Empathy & 97.6 & 15.4 & 101.5 & 14.3 & 5.6 & 0.05 \\
Social Responisbility & 100 & 12.3 & 102.9 & 11.8 & 4 & 0.001 \\
Interpersonal Relationships & 96.2 & 13.5 & 100.2 & 13.1 & 11.2 & 0.001 \\
ADAPTABILITY & 99 & 13.6 & 104.6 & 11 & 16.9 & 0.001 \\
Problem Solving & 98.7 & 10.5 & 103.5 & 11.4 & 12.3 & 0.001 \\
Reality Testing & 98.5 & 14.3 & 103.2 & 12.6 & 11.01 & 0.7 \\
Flexibility & 100.5 & 15.5 & 104.5 & 11.3 & 7.7 & 0.007 \\
STRESS MANAGEMENT & 98.7 & 13.4 & 102.6 & 11.9 & 8.1 & 0.006 \\
Stress Tolerance & 98.8 & 14.1 & 101.9 & 12.7 & 5.4 & 0.023 \\
Impulse Control & 99 & 13.9 & 102.3 & 13.5 & 5.5 & 0.022 \\
GENERAL MOOD & 98.1 & 14.1 & 101.4 & 12.1 & 7.6 & 0.007 \\
Happiness & 98.8 & 15.3 & 101.4 & 13 & 3.9 & 0.051 \\
Optimism & 98.5 & 12.7 & 101.9 & 12 & 9.5 & 0.003 \\
\hline
\end{tabular}

\section{RELEVANCE FOR DEVELOPING ENGINEERS}

To understand why success in the development of key EI competencies is good news for developing engineers, let's revisit the two important components of effectiveness in the new work context - thinking differently and working differently.

\section{Thinking Differently}

In addition to the general recognition of an emotional component in integrative thinking processes discussed earlier in the paper, the capacity for integrative thinking is specifically linked to several of the EI competencies. The ability to craft new models for action, to innovate, and to manage the resulting change is central to the emerging integrative approaches described above, and closely related to the competencies that comprise the composite scale of Adaptability. An individual must be able to engage in personal and interpersonal problem solving (Problem-Solving), calibrate thought and feelings with external reality (Reality Testing), and, perhaps most importantly, be capable of adapting thoughts and feelings to new situations (Flexibility).

A complex, turbulent, and therefore increasingly ambiguous, environment provides the backdrop for the emergence of integrative thinking. In this environment, well-developed self-management competencies are critical to effective action. The ability to be aware of and understand one's emotions (Emotional Self Awareness), to constructively manage those emotions (Stress Tolerance), and to effectively control them when necessary (Impulse Control) is essential. These competencies allow an individual to navigate uncertain terrain while maintaining emotional balance and, with that, the potential to effectively engage others.

Integrative thinking is fundamentally holistic, seeking to integrate many ways of seeing, knowing and understanding. It is a 'both/and' approach that draws on the rational and the emotional, the analytical and the 
intuitive and that is open to embracing seemingly opposing ideas and approaches. It requires that an individual develop rational, analytical competencies as well as competencies related to emotional intelligence. As recognition that integrative thinking is a key component in the development of successful responses to the current work environment grows, so will the interest in strategies to develop emotional intelligence competencies in engineers.

\section{Working Differently}

Deep collaboration is integral to the new work context. It involves working across traditional boundaries and in contexts with unprecedented levels of diversity. In addition to increasing the potential for enhanced creativity, diverse contexts also increase the magnitude of differences and the levels and types of conflict. The ability to work effectively in this context is linked to many of the EI competencies bundled in the Intra- and InterPersonal scales. To be aware of and understand one's emotions (Emotional Self Awareness) is critical and must be balanced with being aware of and understanding how others feel (Empathy). Collaboration also involves the ability to both identify with one's own social group and cooperate with others (Social Responsibility). It also involves the ability to express and act on one's own needs in a way that does not violate the needs of others (Assertiveness). The development of these competencies supports the capability of effective participation in collaborative approaches.

\section{CONCLUSION AND IMPLICATIONS FOR FUTURE WORK}

Enhancing the capacity for thinking differently and working differently are just two examples of the many ways in which the development of EI competencies can be a significant asset to practicing and student engineers as they work in challenging and turbulent work environments. Success in the new work context requires engineers to have both strong disciplinary and inter-disciplinary knowledge along with tools, models and frameworks for analysis and synthesis and well-honed and continuously-improving EI competencies. There is a growing recognition that these are complementary skill sets, yet the intentional development of EI competencies has been largely overlooked by the engineering community. This study makes the case for why the development of EI competencies is important and how this focus can be integrated into engineering development.

While small, the study provides an example of a successful approach to the development of traditionally overlooked competencies that are of strategic importance in the current and future business environment. Given the demands of the external environment and interest in the changing role of the engineer, the study is well timed and provides a foundation for further work. Larger studies, perhaps utilizing control groups, can be planned to further understand the importance of these competencies within the framework of engineering and to fine-tune approaches to their development. Understanding how to integrate the development of these competencies into the engineering curriculum is critical to the future success of engineering programs themselves, the future engineers who graduate from the programs, and, ultimately, to the organizations that they influence.

\section{AUTHOR INFORMATION}

Fredricka F. Joyner is an associate professor of business administration and organization behavior on faculty at Indiana University East. Her teaching, research, and service interests include leadership development, employee engagement, civic engagement, and the scholarship of teaching and learning. In addition, Dr. Joyner maintains an active consulting practice focused on partnering with individuals, organizations, and communities to unleash potential and achieve new levels of performance. E-mail: fjoyner@iue.edu.

Derek T.Y. Mann, Ph.D., is a performance enhancement consultant and has spent several years investigating the impact of emotion on human performance with elite populations which has been published in several leading professional and academic publications and most recently he has co-authored the "Emotional Intelligence Skills Assessment." Given his expertise in this domain, Dr. Mann has also served as a contributing editor to several leading academic and professional journals. Dr. Mann has contributed to the growth and accessibility of emotional intelligence through assessment, training and development, and professional presentations throughout North America. E-mail: Derek.mann.ppg@gmail.com. 
Dr. Todd Harris has served as the Director of Science at PI Worldwide since October, 2002. PI Worldwide is the publisher of the Predictive Index (PI), a personality assessment used by over 7,500 clients in 143 countries. As a member of the PI Worldwide senior management team, Todd advises senior executives from many different industries and countries on the creation and deployment of enterprise-wide talent management strategies, and he is responsible for the scientific rigor that underpins all PI Worldwide toolsets. Todd holds a Ph.D. in Industrial/Organizational Psychology from the University of Connecticut, where his research focused on the areas of performance appraisal, work team effectiveness and organizational culture. E-mail: tharris@piworldwide.com.

\section{REFERENCES}

1. $\quad$ Bar-On, R. (1997). The Emotional Quotient Inventory (EQ-i). Toronto, Canada: Multi-Health Systems, Inc.

2. Bar-On, R. (2004). The Bar-On Emotional Quotient Inventory (EQ-i): Rationale, description, and summary of psychometric properties. In Glenn Geher (Ed.), Measuring emotional intelligence: Common ground and controversy (pp. 111 - 42). Hauppauge, NY: Nova Science Publishers.

3. Beder, S. (1998, April). A bit of the Rain Man in every engineer? Engineers Australia, 57.

4. Beder, S. (1999). Beyond technicalities: Expanding engineering thinking. Journal of Professional Issues in Engineering, 125(1), $12-18$.

5. $\quad$ Boyatzis, R.E., Stubbs, E.C., \& Taylor, S.N. (2002). Learning cognitive and emotional intelligence competencies through graduate management education. Academy of Management Learning and Education, $1(2), 150-162$.

6. Boyatzis, R.E., \& Saatcioglu, A. (2008). A 20-year view of trying to develop emotional, social, and cognitive intelligence competencies in graduate management education. Journal of Management Development, 27(1), $92-108$.

7. Butun, E., Erkin, H. C., \& Altintas, L. (2009). A new teamwork-based PBL problem design for electrical and electronic engineering education: A systems approach. International Journal of Electrical Engineering Education, 45 (2), 110 - 120.

8. Cannon, K. (1999). EQ \& you: Creating your EI development plan. Minneapolis, MN.

9. Crumpton-Young, L. et al. (2010). Engineering leadership development programs: A look at what is needed and what is being done. Journal of STEM Education, 11(3\&4), $10-21$.

10. Culp, G. \& Smith, A. (2009, April). Consulting engineers: Myers-Briggs type and temperament preferences. Leadership and Management in Engineering, 65 - 70).

11. Cummins, Inc. (2011). About Cummins. Retrieved from http://www.cummins.com/

12. Dawda, D. \& Hart, S. (2000). Assessing emotional intelligence: Reliability and validity of the Bar-On E Emotional Quotient Inventory (EQ-i) in university students. Personality and Individual Differences, 28(4), 797-812

13. De Graaff, E. \& Ravensteijn, W. (2001). Training complete engineers: Global enterprise and engineering education. European Journal of Engineering Education, 26(4), 419 - 427.

14. El-Baz, H. S. \& El-Sayegh S. M. (2010). Competency domain model and the perception of engineering managers in the United Arab Emirates. Engineering Management Journal, 22(1), 3 - 12.

15. Goleman, D. (1995). Emotional intelligence: Why it can matter more than IQ. New York: Bantam Books.

16. Harris, T. C., Tracy, A. J. \& Fisher, G. G. (2010). 2010 Predictive Index® technical overview. Wellesley Hills, MA: Praendex Incorporated.

17. Harris, T. C., (2011). The new normal. Wellesley Hills, MA.

18. King, W. J. \& Skakoon, J. G. (2010, December). The unwritten laws of engineering. 132(12) Mechanical Engineering, $43-47$.

19. Lappalainen, P. (2009). Communication as part of the engineering skill set. European Journal of Engineering Education, 34 (2), 123 - 129.

20. Martin, R. (2007, June). How successful leaders think. Harvard Business Review, 85(6), 60-67. Retrieved from EBSCOhost database.

21. Martin, R. (2010, April 13). Fear, loathing, and the MBA. Businessweek.com, 4. Retrieved April 14, 2010, from http://www.businessweek.com/bschools/content/apr2010/bs20100412_325561.htm

22. Martin, R. (2007, November/December). Innovation from the top. The Conference Board Review, 44(6), $14-16$. 
23. Matthews, G., Zeidner, M., \& Roberts, R. (2002). Emotional intelligence: Science and myth. Cambridge: MITPress.

24. Mayer, J. D., Salovey, P., \& Caruso, D. R. (2004). Emotional intelligence: Theory, findings, and implications. Psychological Inquiry, 60, 197-215.

25. Myers, I.B., McCaulley, M.H., Quenk, N.L., \& Hammer, A.L. (1998). MBTI manual: A guide to the development and use of the Myers-Briggs type indicator ( $3^{\text {rd }}$ ed.). Mountain View, CA: Consulting Psychologist Press.

26. Naguib, R. (2007). People skills for engineers. ASHRAE Journal, 2007, 49(10), $78-80$.

27. National Academy of Engineering. (2004). The engineer of 2020: Visions of engineering in the new century. Washington, DC: National Academies Press.

28. Newsome, S., Day, A.L., \& Catano, V.M. (2000). The incremental validity of emotional intelligence. Personality and Individual Differences, 29, 1005-1016.

29. Palethorpe, M. (2006, February - March). Are you emotional but intelligent, or are you emotionally intelligent? IEE Engineering Management, 11 - 13.

30. Parker, J. D. A., Duffy, J., Wood, L. M., Bond, B. J., \& Hogan, M. J. (in press). Academic achievement and emotional intelligence: Predicting the successful transition from high school to university. Journal of FirstYear Experience and Students in Transition.

31. Parker, J. D. A., Hogan, M. J., Eastabrook, J. M., Oke, A., \& Wood, L. M. (2006). Emotional intelligence and student retention: Predicting the successful transition from high school to university. Personality and Individual Differences, 41, 1329-1336.

32. Parker, J. D. A., Saklofske, D. H., Wood, L. M., Eastabrook, J. M., \& Taylor, R. N. (2005). Stability and change in emotional intelligence: Exploring the transition to young adulthood. Journal of Individual Differences, 26, 100-106.

33. Petrides, K.V. \& Furnham, A. (2000). On the dimensional structure of emotional intelligence. Personality and Individual Differences, 29, 313-320.

34. Salovey, P., \& Mayer, J. D. (1990). Emotional intelligence. Imagination, Cognition, and Personality, 9 , 185-211.

35. Slaski, A.M. \& Cartwright, S. (2002). Health, performance and emotional intelligence: An exploratory study of retail managers, Stress and Health, Vol. 18, pp. 63-8.

36. Slaski, A.M. \& Cartwright, S. (2003). Emotional intelligence training and its implications for stress, health and performance, Stress and Health, in press.

37. Sunindijo, R. Y., Hadikusumo, B. H. W., \& Ogunlana, S. (2007, October). Emotional intelligence and leadership styles in construction project management. Journal of Management in Engineering, 23(4), 166 170.

38. Trevelyan, J. \& Tilli, S. (2007). Published research on engineering work. Journal of Professional Issues in Engineering Education and Practice, 133(4), 300 - 307.

39. Van Der Molen, H. T., Schmidt, H. G., \& Kruisman, G. (2007). Personality characteristics of engineers. European Journal of Engineering Education, 32(5), 495 - 501.

40. Van Rooy, D. L., \& Viswesvaran, C. (2004). Emotional intelligence: A meta-analytic investigation of predictive validity and nomological net. Journal of Vocational Behavior, 65, 71-95.

41. Van Rooy, D. L., Viswesvaran, C., \& Pluta, P. (2005). A meta-analytic evaluation of construct validity: What is this thing called emotional intelligence? Human Performance, 18, 445-462.

42. Verzat, C., Byrne, J., \& Fayolle, A., (2009). Tangling with spaghetti: Pedagogical lessons from games. Academy of Management Learning \& Education, 8(3), 356 - 369. 


\section{NOTES}

